\title{
De recolectores a cultivadores certificados: tensiones y articulaciones de saberes territoriales en la Reserva de la Biosfera Los Tuxtlas, Veracruz (México)
}

From Gatherers to Certified Growers: Tensions and Articulations about Territorial Knowledge at the Biological Reserve of the Tuxtlas Biosphere, Veracruz (México)

De coletores a cultivadores certificados: tensões e articulações de saberes territoriais na Reserva da Biosfera Los Tuxtlas, Veracruz (México)

Emilia Velázquez Hernández ${ }^{\star}$

Fernando Ramírez ${ }^{* *}$

Recibido: 7 de marzo de 2019

Aprobado: 11 de octubre de 2019

Doi: https://www.doi.org/10.12804/revistas.urosario.edu.co/territorios/a.7740

Para citar este artículo:

Velázquez Hernández, E., \& Ramírez, F. (2020). De recolectores a cultivadores certificados: tensiones y articulaciones de saberes territoriales en la Reserva de la Biosfera Los Tuxtlas, Veracruz (México). Territorios, (42-Especial), 1-24. https://www.doi.org/10.12804/revistas.urosario.edu.co/territorios/a.7740

* Profesora investigadora
del Centro de Investigacio-
nes y Estudios Superiores
en Antropologia Social,
Unidad Golfo (Méxi-
co). Correo electrónico:
emivel@ciesas.edu.mx.
orCID: https://orcid.
org/0000-0001-6372-7459
* Jefe del Departa-
mento de Biodiversidad
y Cambio Climático del
Ayuntamiento de Xalapa
(Veracruz, México). Correo
electrónico:xate09@gmail.
com. ORCID: https://orcid.
org/0000-0001-6050-5877 
Palabras clave

Territorio agrario, territorio de conservación, saber territorial, área natural protegida.

Keywords

Agrarian territory, conservation territory, territorial knowledge, protected natural area.

Palavras-chave

Território agrário, território de conservação, saber territorial, área natural protegida.

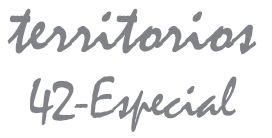

\section{RESUMEN}

En este artículo se discute cómo al amparo de la creación de áreas naturales protegidas se generan nuevas territorializaciones que se sobreponen a territorios y territorializaciones ya existentes. Cada una de estas territorializaciones está anclada a saberes territoriales particulares, que responden a intereses y valoraciones de la naturaleza a veces contrapuestos. Se analizó cómo la creación de un área natural protegida, basada en un saber territorial experto, impactó las modalidades y posibilidades de acceso a recursos forestales esenciales para la economía familiar de varias poblaciones. Mostramos que en torno a la recolección de un recurso forestal no maderable existente en la montaña, los campesinos crearon su propio saber territorial. El cambio de extracción a cultivo de este recurso trastocó dicho saber. Los resultados aquí presentados son producto de un largo trabajo de campo en el que se combinó la investigación-acción y el trabajo etnográfico.

\section{ABSTRACT}

This paper discusses how, in the context of creating a protected natural area, new territorializations are generated that overlap existing territories and territorializations. Each of these territorializations is embedded in particular territorial knowledge, which responds to sometimes conflicting interests and valuations of nature. We analyzed how the creation of a protected natural area, based on expert territorial knowledge, impacted the modalities and possibilities of access to forest resources that were essential for the family economy of several populations. We show that around the harvest of a non-timber forest resource existing in the mountain, the peasants created their territorial knowledge. The change from the resource's extraction to its cultivation disrupted this territorial knowledge. The results presented here are the product of a long-field work that combined action-research and ethnographic work.

\section{RESUMO}

Neste artigo discute-se como é que ao abrigo da criação de áreas naturais protegidas se geram novas territorializações que se sobrepõem a territórios e territorializações já existentes. Cada uma destas territorializações está ancorada em saberes territoriais particulares, que respondem a interesses e valorações da natureza, às vezes contrapostos. Analisamos como a criação de uma área natural protegida, baseada em um saber territorial experto, impactou as modalidades e possiblidades de acesso a recursos florestais essenciais para a economia familiar de várias populações. Mostramos que em torno à colecção de um recurso florestal não madeireira existente na montanha, os camponeses criaram o seu próprio saber territorial. A mudança de extração a cultivo deste recurso prejudicou este saber territorial. Os resultados aqui apresentados são produto de um longo trabalho de campo em que se combinou a pesquisa-ação e trabalho etnográfico. 


\section{Introducción}

En la década de 1990, los campesinos mexicanos, tanto indígenas como mestizos, enfrentaron numerosas innovaciones derivadas de políticas públicas que atañían a sus formas de producción, propiedad de la tierra y acceso y uso de los recursos naturales. Tales innovaciones repercutieron de diversas maneras en los ámbitos económico, político, cultural y socioambiental de las sociedades rurales, que se expresaron también en su organización territorial y los saberes asociados a formas particulares de uso y apropiación de recursos localizados en determinados espacios geográficos. En este contexto, nuestro interés en este artículo es reflexionar sobre cuatro aspectos que desde hace más de veinte años han actuado de manera interrelacionada para afectar los conocimientos y prácticas que sobre sus territorios ejercen las poblaciones rurales: la creación desde el Estado de territorios asociados a la conservación; la imposición de nuevas regulaciones para el acceso a ciertos recursos naturales; la relevancia que en estos procesos han tenido los saberes territoriales producidos por expertos, y los desfases y adecuaciones entre estos últimos y los saberes territoriales creados a partir de prácticas locales de aprovechamiento de recursos.

La observación y la interpretación etnográficas parten de tres hechos empíricos: 1) la conformación de un área natural protegida (ANP) a finales de la década de 1990 sobre una amplia región del sur del estado de Veracruz (México); 2 ) la puesta en marcha de un proceso de reterritorialización mediante la delimitación de espacios antes inexistentes (zonas núcleo y zonas de amortiguamiento) como espacios para la conservación, a los que se asociaron restricciones para el acceso a recursos, a la vez que se abrían posibilidades de obtener apoyos monetarios para financiar proyectos productivos acordes con los planes estatales de conservación, y 3 ) el desplazamiento de la recolección de recursos forestales no maderables en una de las zonas núcleo de la Reserva de la Biosfera Los Tuxtlas, por el cultivo de dichos recursos en parcelas de labor en los ejidos ${ }^{1}$ localizados en la periferia de dicha zona núcleo. Este último fue un proceso que requirió de nuevos aprendizajes campesinos mediados por la intervención de un saber experto indispensable para cubrir las obligaciones previstas por la nueva legislación ambiental, la cual —entre otras cosas - regula el aprovechamiento y comercialización de recursos que han sido clasificados como especies en situación de riesgo de extinción y que por lo tanto están incluidas en la Norma Oficial Mexicana (NOM) 059.²

Nuestro interés, a partir de estos tres eventos, se centra en reflexionar sobre los actos de reterritorialización que acompañan la creación de territorios de conservación (Bluwstein \& Lund, 2018, p. 453). La creación de estos territorios está asociada a dos procesos particulares: la redefinición de espacios determinados que por albergar
${ }^{1}$ El ejido es una forma de propiedad social de la tierra que existe en México, creada para satisfacer las demandas de algunos de los sectores que participaron activamente en la revolución mexicana. La dotación de tierras ejidales generalmente provino de la expropiación de grandes $y$ medianas propiedades privadas, que se otorgaron a grupos de campesinos sin tierra que se organizaron para solicitar la dotación de ejidos. Los lineamientos para la reforma agraria posrevolucionaria quedaron establecidos en el artículo 27 de la Constitución de 1917. A partir de entonces, bubo numerosos cambios que fueron modificando la manera de ejecutar el reparto agrario. Al respecto, Varo (2002) señala que "El ejido [...] se fue conformando con una serie de decretos y bajo la influencia de diversos movimientos campesinos y variadas correlaciones de fuerza dentro del aparato estatal" (p. 114). En 1992, el Estado mexicano declaró el fin del reparto agrario, a la vez que el Congreso modificó el artículo 27 y aprobó una nueva ley agraria que dejaba sin efecto dos

\section{territarias 42-Especial}

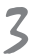


caracteristicas centrales del ejido: su inalienabilidady su inembargabilidad.

${ }^{2}$ La NOM 059 "tiene por objeto identificar las especies o poblaciones de flora $y$ fauna silvestre en riesgo en la República Mexicana, mediante la integración de las listas correspondientes, así como establecer los criterios de inclusión, exclusión o cambio de categoría de riesgo para las especies o poblaciones, mediante un método de evaluación de $s u$ riesgo de extinción y es de observancia obligatoria en todo el Territorio Nacional, para las personas físicas o morales que promuevan la inclusión, exclusión o cambio de las especies o poblaciones silvestres en alguna de las categorias de riesgo, establecidas por esta norma”. Esta reglamentación se estableció para acatar el Convenio sobre la Diversidad Biológica, adoptado en Río de Janeiro, Brasil, el 5 de junio de 1992, y que el gobierno mexicano firmó ad referendum el 13 de junio del mismo año (http://www.profepa. gob.mx/innovaportal/ file/435/1/NOM_059_SEMARNAT_2010.pdf).

\section{territorias 42-Especial}

cierto tipo de recursos naturales han sido revalorados y han adquirido nuevas connotaciones, y el forzoso encuentro/ desencuentro de diferentes tipos de saberes mediante los cuales se conocen y aprecian ciertos espacios y sus recursos, que es lo que denominamos saberes territoriales. En este sentido, son dos los objetivos de este artículo: dar cuenta de los procesos de reterritorialización ligados a la conservación, mediante los cuales se redefinen el acceso y uso de los recursos naturales, e indagar cómo interactúan en estos procesos saberes territoriales construidos desde distintas lógicas, experiencias y expectativas.

El artículo consta de tres apartados y unas reflexiones finales: en el primero de ellos damos a conocer las perspectivas teóricas que guiaron la concepción de este trabajo y el análisis desarrollado, así como la metodología empleada. En el segundo apartado presentamos cuál era la territorialización existente en la Sierra de Santa Marta al momento de la creación de la Reserva de la Biosfera Los Tuxtlas (RBLT), a la vez que mostramos cómo esta territorialización se sobrepuso a una anterior, muchos de cuyos rastros se mantuvieron y se expresaron en la permanencia de ciertas prácticas ligadas al uso de determinados espacios y recursos (Velázquez, 2006). El tercer apartado está orientado a explicar el proceso de creación de un territorio de conservación (RLBT) y cómo esto impactó en las modalidades de acceso a recursos en la más extensa de las tres áreas núcleo de la reserva - la parte alta del volcán Santa Marta-, redefiniendo además las actividades productivas de localidades ubicadas en la periferia de dicha zona núcleo. Terminamos con un apartado de reflexiones finales.

\section{Referentes teóricos y metodológicos}

En términos teóricos nos interesa subrayar la dimensión política del territorio, es decir, las relaciones de poder mediante las cuales se crean, recrean y redefinen los territorios a partir de saberes y prácticas que intervienen en "el establecimiento de un dominio en un área geográfica específica" (Ther Ríos, 2012, p. 5). Este dominio está asociado básicamente a la apropiación de un espacio determinado mediante la creación de marcas diversas sobre la naturaleza, lo que con frecuencia redunda "en conflicto por el espacio limitado y [el] encuentro con otros distintos quienes también marcan y dejan huellas en la apropiación sociocultural del espacio" (Ther Ríos, 2012, p. 5). En el caso que aquí tratamos nos referimos a un territorio que se fue conociendo, delimitando y marcando en torno a la recolección de palma camedor para su comercialización en las partes altas del volcán Santa Marta, al sur del estado de Veracruz (México), a las que desde mediados del siglo $\mathrm{xx}$ comenzaron a acceder campesinos popolucas y mestizos procedentes de distintos poblados de dos municipios (Soteapan y 
Catemaco) ubicados en la región de Los Tuxtlas-Santa Marta.

Sostenemos, por otra parte, que la creación de territorios no es el resultado exclusivo de prácticas y saberes locales - ancestrales o no-, sino también de decisiones y categorizaciones creadas desde ámbitos extralocales en función de intereses ajenos a las poblaciones locales. El caso particular que aquí analizamos se refiere a la creación de territorios de conservación concebidos como actos de poder ejercidos desde el Estado (Bluwstein \& Lund, 2018, p. 453), que pueden ser contestados o adoptados con mayor o menor intensidad y eficacia dependiendo de los contextos locales, regionales y nacionales en los cuales ocurre. Como señalan Bluwstein y Lund (2018), el establecimiento de dichos territorios generalmente supone "la perturbación de configuraciones socio-naturales existentes" y la creación de nuevos mandatos que producen "nuevos regímenes de acceso y autoridad" con relación a los recursos (p. 453). En estos actos de reterritorialización, generalmente las poblaciones locales están excluidas de la toma de decisiones y su participación solo está prevista para el acatamiento y ejecución de aquellas tomadas en las altas esferas políticas (poder ejecutivo y legislativo). La mayoría de las veces estas decisiones responden a presiones y compromisos internacionales (firma de convenios, obtención de financiamientos para la conservación) en los que juegan un papel importante organismos que actúan a escala internacional (GEF, PNUD). Dicha “arbitrariedad política, productora de normatividad y con ausencia de vínculos con la vida sociocultural, una vez que afecta a los territorios vividos, se imbrica con ellos y genera nuevas formas de individuación en los territorios" (Ther Ríos, 2012, p. 11). Es en este sentido que Ther Ríos (2012) señala que el territorio "deviene en hipertexto de tiempos, memorias, imaginarios territoriales, relaciones de poder y conflicto", con "una intensidad acumulada (...) [que] remite así a memorias, tradiciones, usos y costumbres, pero también remite e incluye a lo nuevo, lo emergente" (p. 9).

Esto es, nos interesa explorar la dimensión política del territorio desde la perspectiva de las interacciones entre las políticas estatales y las acciones de aquéllos que mediante prácticas cotidianas han conocido, usado y marcado un espacio, en suma, se han apropiado de un determinado territorio. Mostraremos que en el contexto de dichas interacciones, "lo nuevo, lo emergente" procedente de las políticas de conservación es recuperado para reorganizar sus anteriores conocimientos y prácticas. A la par, nos parece necesario reparar en otros actores sociales: los académicos que clasifican desde sus propias categorías científicas determinado espacio en función de los recursos allí existentes, y los técnicos que desde las organizaciones civiles y con base en un saber científico proponen formas particulares de usar y marcar el espacio. ${ }^{3}$ Esto nos lleva a reflexionar sobre las complejas interacciones
${ }^{3}$ Un caso interesante de la influencia de académicos y técnicos en la redefinición de espacios y recursos se encuentra en el trabajo de Gutiérrez Campo (2019). tersitarios 42-Especial 


\section{territorias} 42-Especial entre saberes locales y científicos, las cuales por supuesto son parte de las relaciones de poder presentes en la creación y recreación del territorio. Por otra parte, partimos de la premisa de que los saberes locales no necesariamente están anclados en la ancestralidad y la inalterabilidad del conocimiento, lo que puede conducir a perder de vista "tanto el carácter dinámico y bullente que adoptan estos saberes en el contexto del mundo contemporáneo, como la naturaleza del complejo proceso por el cual se construyen e inventan nuevos saberes locales" (Landini, 2010, p. 21). Asumimos también que los saberes científicos en contextos de investigación participativa son necesariamente localizados en el proceso de interacción entre técnicos y campesinos, lo cual conduce "a un proceso de reorganización (...) de los conocimientos técnico-científicos al ser incorporados al conocimiento del sentido común de los productores campesinos, lo que permite reconfigurarlos según las particularidades territoriales y culturales locales" (Landini, 2010, p. 37).

La metodología empleada en esta investigación combinó dos modalidades. Por un lado, una larga experiencia de investigación-acción de uno de nosotros, quien durante varios años, y al amparo de una asociación civil, trabajó con grupos de palmeros de varios ejidos de los municipios Soteapan y Mecayapan, con quienes muchas veces recorrió los intrincados caminos y filos del volcán Santa Marta para conocer su experiencia de recolección e identificar las condiciones biológicas de las palmas camedor (Chamaedorea hooperiana $\mathrm{Hodel}$ ) en estado silvestre. Con ellos montó experimentos para el monitoreo de producción y cosecha de hojas en diferentes puntos de la cima y el cráter del volcán. Pocos años después, juntos iniciaron el proceso de experimentación del cultivo de la palma en solares y pequeños espacios de parcelas, además de tomar dos cursos de capacitación con otros productores de palma en el estado de Chiapas (sur de México). Finalmente, cuando el cultivo de palma había sido adoptado por varios grupos de campesinos(as) en distintos ejidos, emprendieron la aventura de conformar una Sociedad de Producción Rural (SPR) para la comercialización de la producción. Esta experiencia de investigación-acción, realizada desde la biología y con una intensa historia de encuentros, desencuentros, negociaciones y acuerdos, se entrecruzó con el trabajo efectuado por otro de nosotros desde un acercamiento antropológico, en el marco institucional de un centro de investigación académica. En este caso, la intención era reflexionar sobre los desfases y contradicciones entre proyectos estatales y locales tomando como hilo conductor la historia agraria. A lo largo de varios años recopilamos información, a veces de manera conjunta y otras más por separado, vía observaciónparticipante y la realización de numerosas entrevistas abiertas, semiestructuradas y estructuradas a los recolectores y productores de palma. También uno de nosotros 
estuvo presente para observar y tomar notas en numerosas asambleas de productores que eran convocadas y guiadas por el otro.

\section{La Sierra de Santa Marta: creación de territorios agrarios y acceso a nuevos recursos}

La planicie del Sotavento veracruzano ${ }^{4}$ es interrumpida por dos macizos montañosos separados por el Lago de Catemaco. Uno de estos macizos es la Sierra de Santa Marta, ${ }^{5}$ conformada por dos volcanes: San Martín Pajapan y Santa Marta, ambos con una de sus caras viendo tierra adentro y otra contemplando el Golfo de México, en el océano Atlántico. En términos político-administrativos, el territorio de esta sierra está actualmente bajo la jurisdicción de cuatro municipios: Mecayapan, Pajapan, Soteapan y Tatahuicapan de Juárez (figura 1).

En cuanto al origen étnico de la población, si tomamos como criterio central el idioma que se habla, predomina la población de origen zoque-popoluca y nahua. De acuerdo con los datos del Censo de Población de 2010, en los cuatro municipios (que reúnen un total de 80135 habitantes) los hablantes de lengua indígena sobrepasan el $60 \%$ del conjunto de la población mayor de tres años, sobresale el municipio de Soteapan que rebasa el 80\% (INEGI, 2010). Siguiendo este criterio lingüístico, actualmente la Sierra de Santa Marta aparece como el núcleo más importante de concentración de población indígena en el conjunto del Sotavento veracruzano. Hasta mediados del siglo Xx, la Sierra de Santa Marta era un conjunto montañoso cubierto en su mayoría por bosques tropicales, con poblaciones establecidas principalmente en su porción sur, sureste y suroeste (figura 2).

Nahuas y popolucas habitaban en las cabeceras municipales de entonces (Pajapan, Mecayapan y Soteapan) y en pequeños poblados ubicados en sus cercanías. Todos ellos vivían de la producción agrícola (esencialmente maíz y frijol), complementada por actividades de recolección, caza y pesca, realizadas en tierras de acceso comunal, cuya posesión les estaba legalmente reconocida (Pajapan) o era simplemente asumida de hecho (Mecayapan y Soteapan). A finales de la década de 1950 y principios de los años sesenta, en los municipios de Soteapan y Mecayapan inició un reparto agrario que concluyó entre finales de la década del 70 e inicios de la siguiente. Una gran parte de los ejidos creados al término de este periodo se fundó al norte y oriente de la Sierra, en un espacio hasta entonces poco habitado, con lo que la frontera agrícola y pecuaria se fue extendiendo paulatinamente sobre las áreas boscosas.

El reparto agrario se tradujo en un proceso novedoso de reterritorialización, en el que se crearon nuevas fronteras en tierras hasta entonces de acceso abierto para la caza, pesca y recolección, pero también para la agricultura y la creación de nuevos centros de población, por parte de nahuas
${ }^{4}$ El Sotavento veracruzano es el área geográfica comprendida entre las cuencas de los rios Cosamaloapan $y$ Coatzacoalcos, donde se identifican varios espacios regionales: la Cuenca de Cosamaloapan, los llanos del rio San Juan, Los Tuxtlas, la Sierra de Santa Marta, la planicie de Acayucan y el corredor industrial Minatilán-Coatzacoalcos. La identificación de espacios regionales varía de acuerdo a los criterios utilizados para zonificar. Asi, por ejemplo, en trabajos elaborados por biólogos, la Sierra de Santa Marta queda incluida en Los Tuxtlas (González, Dirzo \& Vogt, 1997), en tanto que en estudios realizados por antropólogos esta no forma parte de Los Tuxtlas, sino que junto con la planicie de Acayucan y el corredor industrial Minatitlán-Coatzacoalcos se considera parte del Istmo veracruzano (Münch, 1983).

${ }^{5}$ El otro macizo montañoso es la sierra de Los Tuxtlas, en donde sobresale el volcán San Martín Tuxtla.

\section{territorias 42-Especial}

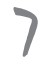


Figura 1. Ubicación y división municipal de la Sierra de Santa Marta

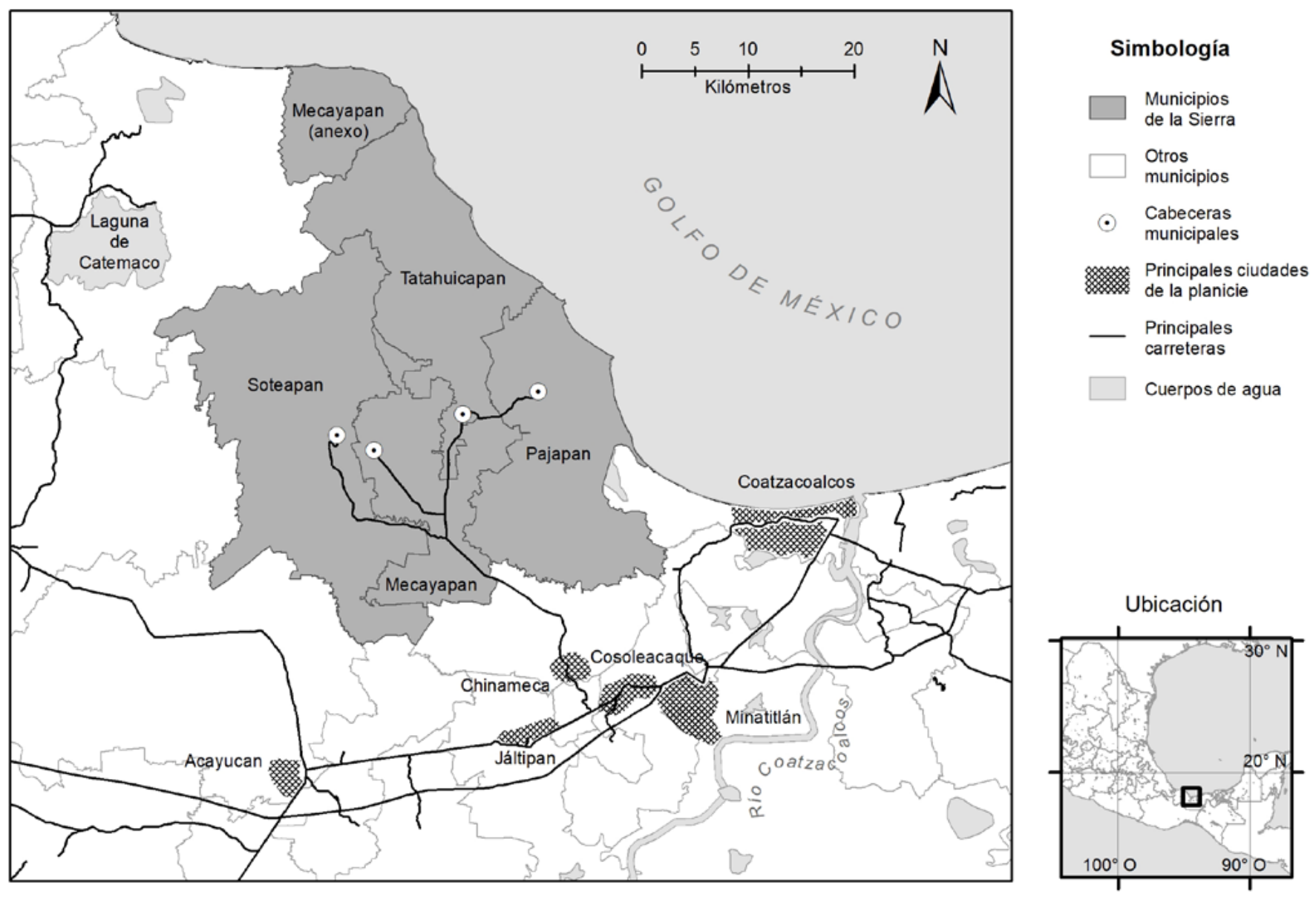

Fuente: Paulo C. López con base en el mapa realizado por Rafael Palma (2005) con el SIG Sotavento, CIESAS IDED y datos vectoriales del INEGI (2015).

tersitarias

42-Especial

8 y popolucas asentados en los municipios de Mecayapan y Soteapan. Con el reparto agrario, estas tierras quedaron divididas en numerosos ejidos a cuyos recursos ya solo tuvieron acceso los habitantes de cada uno (figura 3).
Esta nueva territorialización se construyó sobre la fragmentación de un orden territorial anterior basado en el uso mancomunado de las tierras de la antigua comunidad indígena de Soteapan por parte de nahuas de Mecayapan y popolucas de Soteapan, una de cuyas características 
Figura 2. Poblados existentes en la Sierra de Santa Marta a mediados del siglo xx
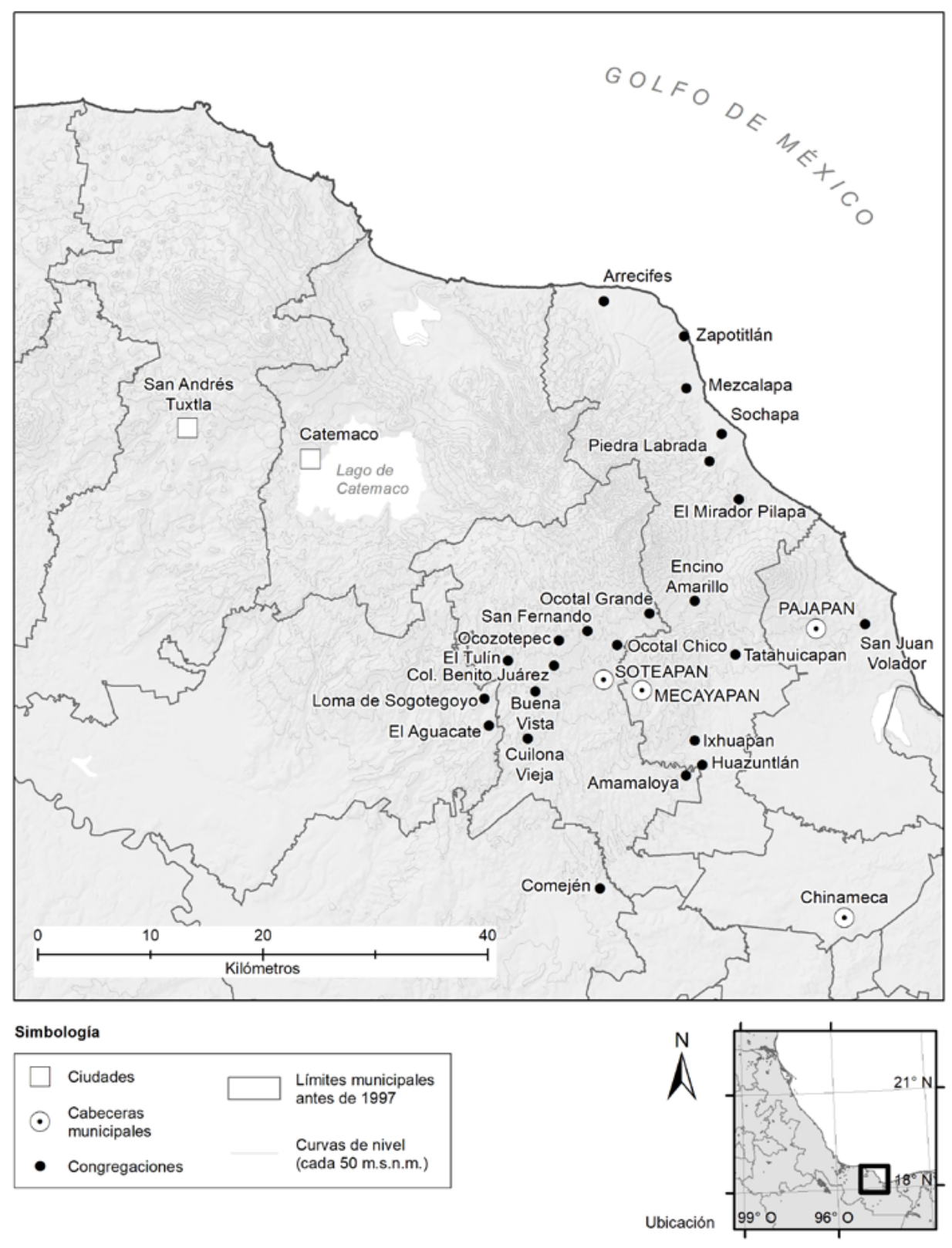

tersitarias 42-Especial

Fuente: Paulo C. López con base en en datos vectoriales del INEGI (2015) en información de Emilia Velázquez.

9 


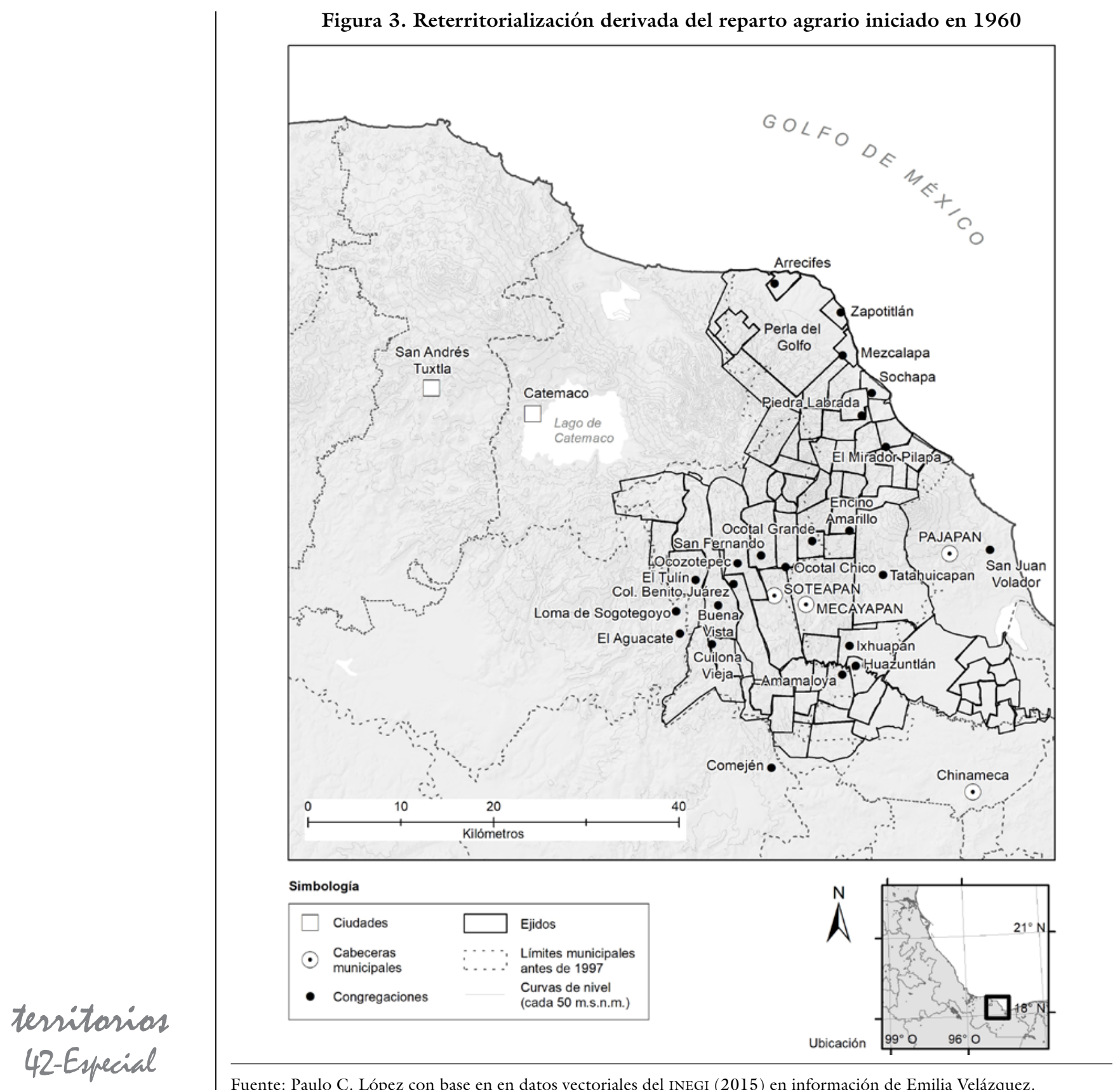

10

Emilia VelázQuez Hernández, Fernando Ramírez 
principales era la existencia de fronteras sumamente laxas entre pueblos e incluso entre municipios. ${ }^{6}$

El proceso de reterritorialización asociado al reparto agrario estuvo acompañado por un aumento en la presión sobre los recursos forestales tanto maderables, como no maderables, generada por la dotación de tierras en áreas hasta entonces cubiertas de selva y en donde se fundaron los nuevos ejidos. En las laderas del volcán Santa Marta y en la contigua serranía El Bastonal-Yohualtajapan, la creación de nuevos ejidos produjo una necesidad urgente de obtener recursos monetarios que permitieran a los ejidatarios adquirir maíz para su supervivencia, mientras abrían tierras al cultivo en terrenos de escasa fertilidad. Una solución a esta necesidad llegó vía la demanda de un recurso forestal no maderable que crecía en abundancia de forma silvestre en la montaña: la palma mayán (Chamedorea hooperiana Hodel).

La demanda de palma provenía de un empresario norteamericano asentado en la cercana ciudad de Catemaco, en donde acopiaba palmas silvestres de varias regiones del sureste del país para después exportarlas a los Estados Unidos (Ramírez, 2005). La extracción de palma camedor para su comercialización era practicada en México, cuando menos desde finales de la década de 1950, los estados de Chiapas, Tamaulipas, Oaxaca, Veracruz, Tabasco y Campeche son los principales proveedores de este recurso forestal no maderable (de los Santos, López \& González, 2003, p. 9).
En el sur de Veracruz, la palma camedor crecía de forma abundante en la Sierra de Santa Marta y la serranía El BastonalYohualtajapan, tal como lo recordaba don Pánfilo, un ejidatario fundador del ejido Miguel Hidalgo (municipio Catemaco), quien contaba que cuando llegaron a vivir a este lugar en 1964 comenzaron a cortar palma "para venderle al gringo". Para ello, se internaban por los filos de la serranía El Bastonal-Yohualtajapan, en donde había tanta palma que era difícil caminar pues las hojas se entrecruzaban unas con otras formando una gran maraña (Manuel, ejidatario de Miguel Hidalgo, entrevista, 05/02/1993). Por su parte, Domingo, un ejidatario popoluca de San Fernando (municipio de Soteapan), recuerda que desde 1965 su abuelo comenzó a subir a la montaña a cortar palma mayán que vendía “a un gringo de Catemaco" (Entrevista con Domingo Pablo Rodríguez, 30/04/2018).

De esta forma, para varias poblaciones - principalmente popolucas pero también algunas mestizas - ubicadas en las cercanías de las laderas altas y escarpes de la vertiente suroccidental y occidental del volcán Santa Marta, en los municipios de Soteapan y Catemaco, la recolección de palma camedor se volvió una importante fuente de ingresos a partir de mediados de la década de 1960, a la par que incursionaban en el cultivo de café. A principios de la década de 1990, un ejidatario de Miguel Hidalgo (municipio de Catemaco), señalaba que "desde hace 25 años que
${ }^{6}$ Por ejemplo, campesinos del poblado Soteapan tenian sus fincas de café en las inmediaciones de la vecina localidad San Fernando, pertenecientes ambas al municipio de Soteapan. En tanto que, entre las décadas de 1940 y 1950, grupos familiares de nabuas que habitaban en el pueblo de Mecayapan abrieron sus milpas en terrenos del municipio de Soteapan, donde poco después establecieron su lugar de residencia. Es el origen de los actuales poblados Mirador Saltillo y San Miguel Chamilpa, cuyos babitantes decidieron, en el primer caso, adscribirse al municipio de Soteapan y en el segundo permanecer bajo la jurisdicción del municipio de Mecayapan (Velázquez, 2006).

\section{territarias 42-Especial}

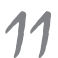


${ }^{7}$ La escritura del nombre de la sierra varía según se trate de documentos académicos y gubernamentales (Sierra de Santa Marta)o del ejido que lleva el mismo nombre $y$ que oficialmente se denomina Sierra de Santa Martha. Por ello, en este artículo se usan las dos formas de escritura, una para referirse a la sierra en su conjunto y al volcán más alto de la misma, y otra para aludir al ejido.

${ }^{8}$ Los datos proceden de dos talleves de planeación comunitaria realizados en 1993 en estos ejidos, en los que tuvimos oportunidad de participar. El estudio completo puede consultarse en Velázquez y Ramirez (1995).

9 En la década de 1990, para la realización de un diagnóstico sobre el estado de las poblaciones silvestres de palma, uno de los autores (F. R.) de este texto subió varias veces a la montaña con palmeros del ejido Sierra de Santa Martha.

\section{territorias 42-Especial}

se fundó el ejido hemos vivido de la palma" (Entrevista con Manuel ejidatario de Miguel Hidalgo, 05/02/1993). Por la misma época comenzaron a sembrar las primeras matas de café, que obtuvieron regaladas en un poblado (La Magdalena) del municipio de Soteapan a donde iban a trabajar como jornaleros (Entrevista con Carmen Pablo, 18/02/1992). En las siguientes décadas, la extracción y venta de palma mayán —igual que el cultivo de café- siguieron siendo una fuente de ingresos para estos campesinos.

A principios de los años noventa, en el ejido Miguel Hidalgo (municipio de Catemaco) eran treinta los campesinos que durante ocho meses al año se internaban semanalmente en la selva para cortar palma mayán. Por su parte, en el ejido Sierra de Santa Martha ${ }^{7}$ (municipio de Soteapan) había 35 campesinos que subían a la montaña a cortar palma mayán, de dos a cuatro días por semana durante seis meses al año. En conjunto, los campesinos de estos dos poblados extraían aproximadamente 2625600 varas de palma; ${ }^{8}$ también pobladores de Ocotal Grande, San Fernando, Emiliano Zapata, Guadalupe Victoria y Plan Agrario (pertenecientes al municipio de Soteapan los cuatro primeros y al de Mecayapan el último de ellos) se internaban en la selva para cortar palma mayán (figura 4). La recolección de palma podía realizarse durante todo el año, aunque la mayor extracción ocurría en la época de secas (marzo-mayo), la cual se reducía durante la temporada de lluvias (julio-septiembre).

Los recolectores se internaban en la selva en busca de manchones de palma, y una vez que ubicaban uno empezaban a cortar las hojas con una navaja y enseguida las depositaban en un costal que llevaban colgado al hombro. ${ }^{9}$ A veces, de cada tallo solo se podía recolectar una hoja, pero si se encontraban tallos con varias hojas de características comerciales las cortaban todas. El siguiente paso era acomodar las palmas en manojos de 60 hojas, agrupando dos manojos por "gruesa", que era la medida de venta. Era un trabajo pesado:

salíamos de San Fernando a las 2 de la mañana, agarrábamos a un lado del arroyo Huazuntlán y por ahí nos íbamos caminando, llegábamos a eso de las 8 de la mañana a donde había palma y nos regresábamos a las 2 de la tarde (Entrevista con Domingo Pablo Rodríguez, 30/04/2018).

A sus casas llegaban entre las seis y siete de la tarde. Había ocasiones, en el mes de septiembre, en que subían a la montaña con la intención de regresar el mismo día, pero si caía un aguacero fuerte y el río Huazuntlán crecía mucho, ya no podían volver al pueblo pues cruzar el río era imposible, así que debían quedarse a dormir casi a la intemperie. Raymundo rememora esos años y dice "sufrí mucho allá [en la montaña]" (Entrevista con Raymundo Márquez, 01/05/2018). 
Figura 4. Área de recolección de palma camedor y poblados de los que provenían los recolectores de palma
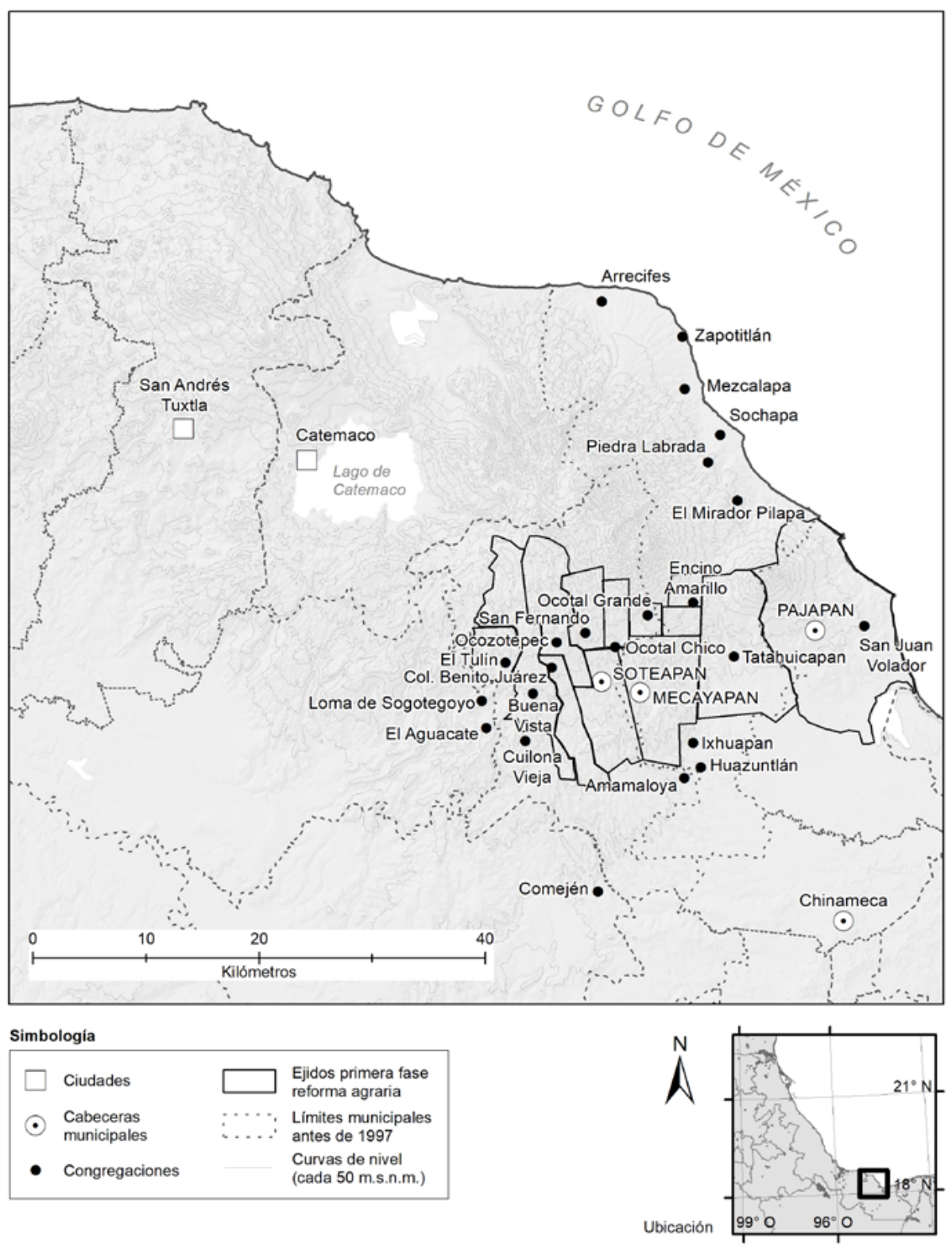

Fuente: Paulo C. López con base en en datos vectoriales del INEGI (2015) en información de Emilia Velázquez.

DE RECOLECTORES A CULTIVADORES CERTIFICADOS: TENSIONES Y ARTICULACIONES 
Cada recolector organizaba su salida por su cuenta, acompañándose con algún familiar. Domingo, por ejemplo, comenzó a subir a la montaña en compañía de su padre cuando tenía 16 años, aunque ya en el camino, o en lo alto de la montaña, solían encontrarse a otros cortadores, tanto de San Fernando como de Ocotal Grande y Santa Martha. Raymundo, por su parte, se inició como recolector de palma a los 12 años, bajo la tutela de un tío suyo. A esa edad, él solo podía cargar 6 gruesas completas, en tanto que los adultos regresaban con una carga de entre 10 o 12 (Entrevista con Raymundo Márquez, 01/05/2018). Los recolectores subían a la montaña y regresaban el mismo día, para lo cual invertían más de doce horas entre la recolección, la espera a que disminuyera el sol y el calor antes de regresar y así evitar que las hojas de palma se "quemaran", más los trayectos de ida y vuelta. También había quienes optaban por quedarse varios días para cortar más palma. Raymundo, por ejemplo, llegó a permanecer en la montaña cerca de una semana. Lo acompañaba su esposa, quien además de cortar palma hacía la comida, para lo cual llevaban consigo harina de maíz y huevos. Esto solo podían hacerlo cuando conseguían caballos prestados para transportar la palma cortada durante varios días. La gente que acampaba aprovechaba para cazar animales silvestres (faisán, jabalí, mazate) para comer en el monte y llevar de regreso al pueblo. La caza no se practicaba cuando se regresaba el mismo día, pues "no podíamos distraernos persiguiendo algún animal".

Determinado día de la semana, el acopiador de la palma, quien trabajaba para el dueño de la empresa exportadora asentada en Catemaco, llegaba al pueblo de Soteapan a recoger el producto, por lo que ese día los cortadores de Ocozotepec, Ocotal Grande, Ocotal Chico, Santa Martha y San Fernando debían trasladarse a la cabecera municipal para entregar su palma. La mayoría caminaba desde sus localidades, pues en los años 1960-1990 no había transporte rural y solo muy pocas personas contaban con caballo - "éramos pobres, casi nadie tenía caballo" (Entrevista con Raymundo Márquez, 01/05/2018)-.

La recolección de palma se intensificó con el paso de los años, por lo que cada vez había que invertir más trabajo para obtener las hojas. Conforme aumentaba el número de personas que subía a la montaña por palma, el recurso empezó a escasear: "teníamos que caminar más lejos para encontrar la palma". Por ejemplo, cuando Raymundo comenzó a recolectar palma en 1970 , él y su tío caminaban tres horas y media desde San Fernando hasta el lugar de recolección, en tanto que cuando Domingo se inició como cortador de palma en 1998, debía caminar casi 6 horas, también partiendo de San Fernando. Con base en recorridos de campo realizados a mediados de la década de 1990 con recolectores de palma, Ramírez (2005) registró: 
Las poblaciones de palmas más cercanas a los poblados han sido exterminadas por la sobreexplotación a la que fueron sometidas en los últimos diez años (...) la mayoría de las poblaciones silvestres de palma bajo aprovechamiento se encuentran en los lugares más alejados e inaccesibles [del volcán Santa Marta] (p. 39).

Por ello, una vez que los recolectores llegaban a estos sitios, debían dedicar tiempo a buscar plantas en buen estado: "caminábamos unas 2 hectáreas, a veces más, pues las plantas ya casi no tenían hojas buenas", es decir hojas de tamaño adecuado para su comercialización (Entrevista con Domingo Pablo Rodríguez, 30/04/2018).

Ir a la montaña a recolectar palmas requería ciertos aprendizajes que se transmitían de padres a hijos, de abuelos a nietos o de tíos a sobrinos. Antes de entrar a la montaña se quemaba copal y una mecha de algodón sobre una piedra, generalmente junto a un río o arroyo, con el fin de no sufrir algún percance durante el camino - una caída, una mordedura de víbora- (Cuaderno de Campo de Fernando Ramírez, 1994). Además, había que saber "por dónde entrar y salir de la montaña", algo que Domingo aprendió de su padre. A Raymundo, por su parte, fue su tío quien le enseñó a andar en la montaña: "en ese tiempo [cuando comencé a recolectar palma] yo no conocía la selva, uno se puede perder por allá”. También había que aprender a escoger y cortar las hojas, acomodarlas y transportarlas hasta la casa.

Esta recolección se realizaba sin ningún tipo de reglamentación local. Se trataba de un recurso de acceso abierto, que crecía en forma silvestre en tierras nacionales y que podía explotar cualquier miembro de las localidades aledañas al volcán, sin ninguna restricción por parte de las autoridades. La necesidad de un número creciente de familias campesinas de obtener ingresos con los que completar lo obtenido por sus labores agrícolas, sumada a la inexistencia de un orden mínimo para la extracción de palmas, condujo a una grave sobreexplotación del recurso. Con la intención de resolver este problema que amenazaba la supervivencia misma de las palmas, una $\mathrm{ONG}^{10}$ que comenzó a trabajar en la región en 1990 intentó proponer un plan de manejo de este recurso silvestre. Sin embargo, un plan de tal naturaleza requería necesariamente del involucramiento de todos los cortadores de palma de las distintas localidades que hacían uso de este recurso, a lo que fue imposible arribar. A pesar de que en varias localidades se reconocían las ventajas que esto podría tener para asegurar la continuidad de la extracción, no se logró establecer ninguna reglamentación para un recurso de acceso abierto, localizado en tierras nacionales sobre las que ninguna autoridad local (comisario ejidal, presidente municipal) tenía jurisdicción.

Así, la territorialización agraria generada por el reparto agrario desplazó casi
${ }^{10}$ Se trata del Proyecto Sierra de Santa Marta, AC (ver http://proyectosantamarta.blogspot.com/) del que los autores de este articulo, junto con otros colegas, fuimos miembros fundadores. Más información sobre los trabajos de esta asociación civil pueden consultarse en Paré, Velázquez, Ramirez y Graciano (2017).

\section{territarias 42-Especial}


${ }^{11}$ El reparto agrario en la Sierra de Santa Marta sirvió, en parte, para resolver solicitudes de tierra de otras regiones de la entidad veracruzana en las que por diversos motivos ya no habia tierras para repartir. El ejido Miguel Hidalgo, por ejemplo, se formó con gente proveniente de los municipios de Perote y Altotonga, ubicados en el centro-occidente del estado de Veracruz. Una parte de las tierras ejidales de $M i$ guel Hidalgo se localizan en la ladera occidental del volcán Santa Marta.

${ }^{12}$ La captura y venta de esta ave dejó de realizarse en la década de 1990. Actualmente, en México es una especie protegida por la NOM 059.

\section{territorias 42-Especial}

por completo a la antigua territorialización fincada en el uso mancomunado de tierras y el acceso comunal a tierras para uso agrícola, al mismo tiempo que suscitó el uso de otros espacios y el acceso abierto a sus recursos. La territorialización ejidal produjo nuevas fronteras agrarias y agrícolas: a partir de entonces, los campesinos de cada ejido solo pudieron hacer un uso productivo de las tierras disponibles al interior de sus ejidos. Además, trajo consigo la creación de nuevos poblados y el avance de la frontera agrícola hacia las laderas poco fértiles del volcán Santa Marta. ${ }^{11}$ En este contexto, de un mayor número de personas haciendo uso de terrenos, ahora acotados a los polígonos de las tierras ejidales repartidas por el Estado y de la llegada de nuevos pobladores que debieron comenzar desde cero a fundar sus núcleos urbanos y abrir terrenos para la agricultura, la demanda de un recurso específico de las selvas tropicales propició la exploración de la montaña que por su ubicación y topografía no fue incluida en el reparto agrario, por lo que permaneció bajo el estatuto de tierras nacionales.

La recolección de la palma camedor como nueva opción para la obtención de ingresos monetarios condujo a una apropiación casi cotidiana de un espacio - el exterior e interior del cráter del volcán Santa Marta- que hasta entonces había sido poco conocido y transitado. En estrecha relación con esta actividad de recolección se fue elaborando un saber territorial mediante el cual se abrían y reconocían nuevas veredas, se ubicaban nuevos manchones de palma, se identificaban arroyos que indicaban la presencia de áreas favorables para la cacería de tepezcuintles, mazates, faisanes y otros animales de monte muy apreciados en la alimentación popoluca. El conocimiento de este espacio condujo, más tarde, a una nueva actividad económica por parte de algunos campesinos popolucas de los ejidos San Fernando y Sierra de Santa Martha: la captura de clarín (Myadestes occidentalis), un pájaro muy apreciado por su canto. ${ }^{12}$

\section{La creación de un área natural protegida: desfases $y$ articulaciones de saberes territoriales}

A finales de la década de 1990, a la territorialización agraria de los años 1960-1970 se sobrepuso una nueva territorialización, ahora ligada a la conservación de los recursos naturales. Por sus características biológicas, desde años atrás, la Sierra de Los Tuxtlas y la vecina Sierra de Santa Marta habían sido objeto de políticas orientadas a la protección de sus recursos naturales. La primera de estas políticas data de 1937 , cuando el presidente de la república —el general Lázaro Cárdenas- decretó la creación de la Zona Protectora Forestal Vedada de la Cuenca Hidrográfica del Lago de Catemaco. En 1979 y 1980, también desde el ámbito federal, se decretaron las Zonas de Protección Forestal y Refugio de la Fauna Silvestre en los volcanes San 
Martín Tuxtla y Santa Marta-San Martín Pajapan, esta última fue reclasificada como Reserva Especial de la Biósfera en 1988. Tales decretos, sin embargo, no tuvieron mayores consecuencias en cuanto al acceso y uso de los recursos naturales por parte de las poblaciones humanas que habitaban en estas ANP. Tampoco se detuvo el deterioro que se quería evitar respecto a la extracción masiva de madera de la selva tropical, que en el caso de la Sierra de Santa Marta se fue talando a la par que se creaban colonias agrícolas y ganaderas (El Bastonal, La Perla del Golfo y La Magdalena), se fundaban numerosos ejidos y se extendía la ganadería bovina principalmente al oriente y norte. ${ }^{13}$

Para hacer frente a situaciones de este tipo, y en un contexto nacional e internacional de presión creciente para que los Estados nacionales tomaran medidas efectivas para la conservación de recursos naturales de diverso tipo, desde el Estado mexicano se crearon varias instituciones de gobierno y promulgaron leyes dirigidas a asegurar la conservación de los recursos naturales (bosques, fauna, flora, cuerpos de agua) existentes en la nación. ${ }^{14}$ Fue en este marco, que en la región de estudio el gobierno federal derogó las anteriores zonas de protección a los recursos forestales y faunísticos y, en su lugar, creó una sola área natural protegida de mayor extensión. Así, en 1998, por decreto presidencial, se estableció la RBLT, la cual se extiende sobre 155122 hectáreas distribuidas mayoritariamente en la Sierra de Los Tuxtlas y la Sierra de Santa Marta. ${ }^{15}$

Esta reserva está constituida por tres zonas núcleo: San Martín Tuxtla (9823 hectáreas), Santa Marta (18 033 hectáreas) y San Martín Pajapan (1 883 hectáreas), que en conjunto suman 29739 hectáreas. Las restantes 125402 hectáreas incluidas en el decreto corresponden a una zona de amortiguamiento, la cual representa el $80 \%$ de la superficie total de la reserva. ${ }^{16}$ En contraste con las anteriores declaraciones de zonas de protección forestal y faunística, esta vez al decreto de formación de la RBLT le siguió la creación de un aparato administrativo encargado de esta, la elaboración de un plan de manejo (CONANP, 2006) y la canalización de fondos gubernamentales e internacionales para la puesta en marcha de proyectos productivos encaminados a vincular la conservación con el desarrollo. Igual que en otras partes del mundo, la creación y puesta en marcha de la RBLT se inscribió en el modelo de "conservación basada en la comunidad" (community based conservation), con los mismos defectos señalados por algunos autores (Goldman, 2003; Bluwstein \& Lund, 2018).

La creación de la RBLT condujo a la redefinición de un territorio que hasta entonces solo conocía fronteras relacionadas con la propiedad de la tierra (ejidos, propiedad privada, tierras nacionales) y las divisiones municipales. Ahora, a estas fronteras se sobrepusieron nuevos límites que indicaban áreas en las que quedaba
${ }^{13}$ A partir de un análisis de fotografías aéreas, $R a$ mirez (1999) identificó que, en 1967, la superficie cubierta por selva en la Sierra de Santa Marta era de 96640 hectáreas, en tanto que para 1976, la extensión era de 60857.

${ }^{14}$ La formulación de un nuevo marco normativo inició en 1982, cuando "se reformó la Constitución para crear nuevas instituciones y precisar las bases juridicas y administrativas de la politica de protección ambiental”. En ese año, se creó la Secretaría de Desarrollo Urbano y Ecología (SEDUE) "para garantizar el cumplimiento de las Leyes y reorientar la politica ambiental del pais" (bttp:// www.semarnat.gob.mx/ conocenos/antecedentes). También en 1982, se promulgó la Ley Federal de Protección al Ambiente; cinco años más tarde, en 1987, "se facultó al Congreso de la Unión para legislar en términos de la concurrencia a los tres órdenes de gobierno, en materia de protección al ambiente" (bttp://www.semarnat.gob.mx/conocenos/ antecedentes). En consecuencia, un año después se publicó la Ley General

territarios 42-Especial 
$\Leftarrow$

del Equilibrio Ecológico y Protección al Ambiente (LEEGEPA), la cual rige hasta abora la politica ambiental del pais. En 1992, la SEDUE fue transformada en Secretaria de Desarrollo Social (SEDESOL), a la par que se creaba el Instituto Nacional de Ecología (INE) y la Procuraduría Federal de Protección al Ambiente (PROFEPA). En diciembre de 1994, se decretó la formación de la Secretaría de Medio Ambiente, Recursos Naturales y Pesca (SEMARNAP), la cual en noviembre del año 2000 fue reemplazada por la Secretaría de Medio Ambiente y Recursos Naturales (SEMARNAT). Esta Secretaría "es la dependencia del gobierno federal encargada de impulsar la protección, restauración y conservación de los ecosistemas y recursos naturales y bienes y servicios ambientales de México, con el fin de propiciar su aprovechamiento $y$ desarrollo sustentable" (bttp:// www.semarnat.gob.mx/ conocenos/quienessomo).

15 Aproximadamente el $70 \%$ de esta superficie es propiedad ejidal y el resto es propiedad privada.

${ }^{16}$ En 2010, en esta extensa zona de amortiguamiento

$\Rightarrow$

territarias 42-Especial prohibido el acceso para la utilización de recursos ahí existentes (zonas núcleo) y áreas (zonas de amortiguamiento), cuyos habitantes podrían tener acceso a recursos financieros especiales relacionados con la conservación (figura 5 ). Este territorio para la conservación se postuló con base en saberes territoriales de expertos externos que identificaron y cuantificaron superficies arboladas, tipos de vegetación, especies endémicas, especies amenazadas, etc.

A partir de entonces, el área de extracción de palma del volcán Santa Marta quedó clasificada como una de las tres zonas núcleo de la RBLT y la más extensa (18033 hectáreas) de todas. Esto supuso la prohibición absoluta de uso de los recursos ahí existentes, lo que resultaba prácticamente imposible de lograr pues, pese a la declaratoria de la RBLT, esta área siguió estando bajo el control de hecho de quienes sabían "cómo entrar y salir de la selva", es decir, de los recolectores de palma. Se hizo patente, entonces, el enorme desfase entre el "saber territorial" de quienes mediante el uso de cierta tecnología (imágenes de satélite, interpretación de fotografías aéreas, sistemas de información geográfica) tenían el poder de identificar, delimitar polígonos y cartografiar territorios de conservación, y aquellos que, sin un interés ni poder semejante para marcar y definir territorios, contaban con un “saber territorial" elaborado en la práctica constante de subir a la montaña, recorrer la selva e identificar los recursos que podían serles útiles. Tal desfase anunciaba un rotundo fracaso en los objetivos de conservación.

Sin embargo, en los años siguientes ocurrió un paulatino abandono de la extracción de palma y una disminución de la presión humana sobre los recursos de la zona núcleo. Si bien este hecho no provino de la prohibición de hacer uso de las zonas núcleo de la RBLT, sí fue una consecuencia de la existencia de esta última, evidenciando los diferentes efectos que tienen los intentos de creación de territorios de conservación en distintos momentos históricos.

A diferencia de los nulos resultados que en Los Tuxtlas y la Sierra de Santa Marta tuvieron los decretos de zonas de protección forestal y faunística de los años 1979 y 1980, cuando se creó la RBLT el paradigma de la conservación basada en el desarrollo comunitario era asumido no solo por organizaciones no gubernamentales, sino también por instituciones gubernamentales del sector ambiental. Esto posibilitó la canalización de recursos financieros nacionales e internacionales, gubernamentales y no gubernamentales para "implementar alternativas productivas que impulsen el desarrollo en la Reserva [y] Lograr el manejo sostenible de los recursos presentes, por parte de la población local" (CONANP, 2006, p. 100).

Fue en este contexto que, mediante la intervención activa de la misma asociación civil que había intentado crear un plan de manejo para la recolección de palma camedor en los años 1990, pequeños 
Figura 5. Reserva de la Biosfera Los Tuxtlas: la creación de una nueva territorialización

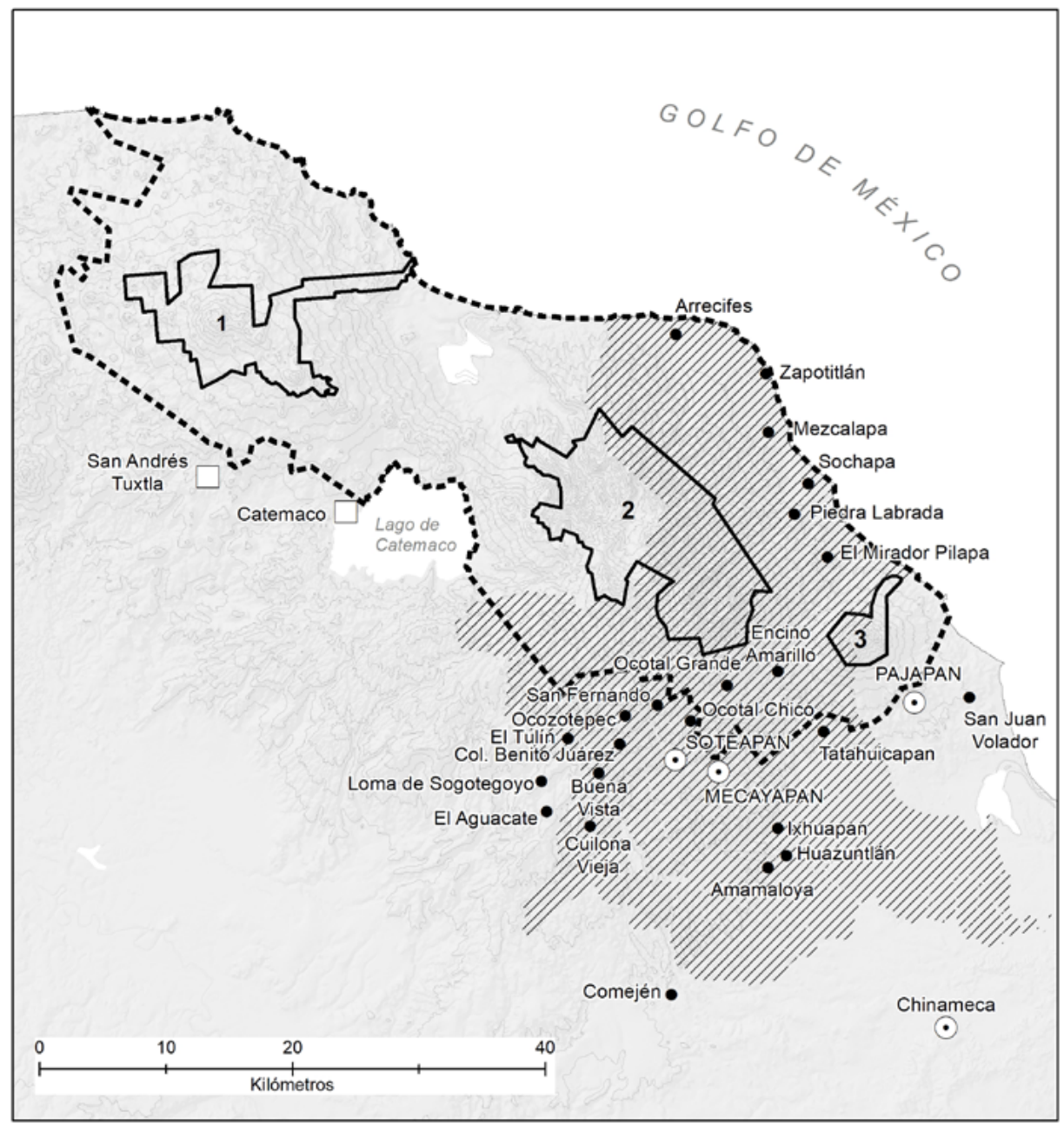

Simbologia

$\begin{array}{lll}\square \text { Ciudades } & \text { VI///, Área de Ejidos } & \square \text { Zonas núcleo } \\ \begin{array}{lll}\text { Cabeceras } \\ \text { municipales }\end{array} & \begin{array}{l}\text { Reserva de la } \\ \text { Biósfera de Los Tuxtlas } \\ \text { Curvas de nivel } \\ \text { (cada } 50 \text { m.s.n.m.) }\end{array} & \begin{array}{l}\text { 2 Volcán de } \\ \text { Santa Marta }\end{array} \\ \text { Congregaciones } & & \text { San Martín Pajapan }\end{array}$

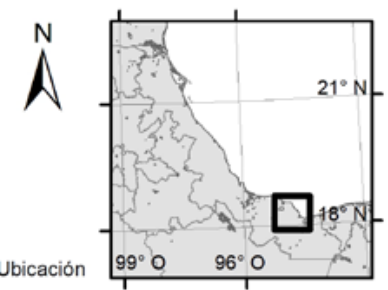

Fuente: Paulo C. López con base en en datos vectoriales del INEGI (2015) en información de Emilia Velázquez.

DE RECOLECTORES A CULTIVADORES CERTIFICADOS: TENSIONES Y ARTICULACIONES
$\Longleftarrow$

habitaban 28625 personas distribuidas en 362 asentamientos humanos, la mayoría de ellos caserios y rancherias (INEGI, 2010).

territarias 42-Especial 
grupos de palmeros en los ejidos Sierra de Santa Martha y San Fernando comenzaron a establecer viveros con diferentes tipos de palmas. Los apoyos financieros iniciales provinieron de fundaciones internacionales (Novib, MacArthur, Ford) y del Programa de Desarrollo Regional Sustentable (PRODERS). Este programa gubernamental fue creado específicamente para

la implementación de acciones y proyectos dentro de las regiones prioritarias para la conservación, que deben dirigirse principalmente a promover la conservación de la zona núcleo o zonas de alta biodiversidad, mejorar las condiciones de producción de las comunidades asentadas en la poligonal de las áreas naturales protegidas o dentro de los municipios que integran las regiones prioritarias y contener los procesos de deterioro ambiental (https://www.inforural. com.mx/programa-de-desarrollo-regionalsustentable-proders-2/).

Comenzó entonces un largo proceso para transitar de la extracción de palmas en la montaña, a su cultivo en las parcelas ejidales. Esto requirió nuevos aprendizajes tanto técnicos, como sociopolíticos: recolectar semilla, hacer viveros, ubicar espacios adecuados en las parcelas para establecer las plantaciones, cosechar siguiendo nuevos estándares de calidad, formar grupos de productores para solicitar recursos gubernamentales, entregar reportes a las agencias financieras, tomar cursos de capacitación, recibir a funcionarios y técnicos del sector ambiental que eventualmente realizaban alguna supervisión. Todo ello supuso la necesaria intervención de un saber experto - un biólogo-que mediara entre los saberes territoriales locales y los saberes territoriales institucionales. Esto se volvió particularmente necesario cuando se pasó a la fase de comercialización de la palma cultivada, para lo cual se debió crear una Sociedad de Producción Rural (SPR) y una Unidad de Manejo Ambiental (UMA) con su respectivo plan de aplicación, condición obligada para que la Secretaría de Medio Ambiente y Recursos Naturales (SEMARNAT) otorgara los permisos de aprovechamiento de palmas para comercializarlas legalmente.

Hoy en día, la extracción de palma en la montaña casi ha dejado de practicarse por completo en las localidades popolucas que hasta finales de los años 90 tenían esta actividad como una fuente de ingresos necesaria.

Empecé a cultivar palma en el año 2000, en 2003 entré al grupo de palmeros, sembrando de poquito, unas 600 plantas. $\mathrm{Mi}$ abuelo, que vivía en [el ejido] Santa Martha, me regaló plantas de mayán que trajo de la montaña. Luego, [en el grupo de palmeros] me dieron 10 kilos [de semilla] que sembré. En 2006 empecé a vender palma de mi cultivo. Ese mismo año junté 20 kilos de semilla para hacer nuevos camellones y producir más plantas. 
Este productor rememora que mientras sus plantas de palma crecían, él siguió yendo a la montaña a cortar palma, pero

desde 2006 ya no subo a la montaña [...] de aquí [San Fernando] ya nadie va a la montaña. Ahora salimos de nuestras casas a las 8 de la mañana para ir a cortar la palma [a las plantaciones al interior del ejido] y a las 4 de la tarde ya estamos de regreso (Entrevista con Domingo Pablo Rodríguez, $30 / 04 / 2018)$.

Otros productores comenzaron antes con el cultivo de la palma:

yo comencé a sembrar palma como por 1995, poquito, no teníamos mucho apoyo, ya después Fernando [el biólogo que trabajaba con ellos y coautor de este artículo] nos consiguió más recursos. Ya en el 2000 empecé a vender a los coyotes mi palma cultivada y dejé de ir a la montaña. Hace unos 8 años fui por última vez a la montaña, por curiosidad, el camino sigue, todavía suben [a extraer palma] algunos que nunca sembraron su palma (Entrevista con Raymundo Márquez, 01/05/2018).

Para quienes se iniciaron temprano en el cultivo de palma y utilizaron debidamente los apoyos gubernamentales, sus plantaciones actuales representan un patrimonio importante que les permite cubrir necesidades básicas de alimentación, educación y salud: “el año pasado operaron a mi esposa de quistes en la matriz, y gracias a la palma salimos [del problema]" (Entrevista con Raymundo Márquez, 01/05/2018).

\section{Reflexiones finales}

El proceso de reterritorialización ligado a la conservación de recursos que hemos analizado en este documento se llevó a cabo a partir de un saber territorial experto mediante el cual se reclasificaron y revaloraron las laderas altas y el cráter del volcán Santa Marta, que hasta principios de la década de 1960 habían sido poco utilizados, pero que a lo largo de dos décadas y media de uso frecuente para la extracción de la palma camedor se transformaron en territorios de los palmeros, quienes en este lapso marcaron de diversas maneras este espacio, abriendo rutas, ubicando los lugares en los que había los mayores núcleos de palma camedor en estado silvestre, aprendiendo a capturar clarines, en fin, desarrollando y consolidando un saber palmero territorial propio. Para estos, la montaña se volvió fuente de recursos fundamentales para la obtención de ingresos monetarios que, junto con el cultivo y venta de café, les permitían su manutención familiar. Tales recursos adquirieron mayor relevancia, a la vez que se intensificaba su aprovechamiento, con la caída abrupta y dramática del precio internacional del café a partir de 1989 y el posterior cierre y desmantelamiento del Instituto Mexicano del Café. Por otra parte, para biólogos y funcionarios del tersitarios 42-Especial 


\section{territorias 42-Especial}

gobierno vinculados a las tareas de conservación, la montaña representaba un reducto cada vez más disminuido de selva tropical que albergaba especies vegetales y animales en peligro de extinción que era necesario proteger. Esta última valoración, avalada por un saber experto, fue la que prevaleció para que el gobierno federal decretara la creación de la RBLT.

Sin embargo, la sola realización de este acto de poder mediante el cual se redefinió el acceso a un espacio ya apropiado no era suficiente para garantizar la conservación. Hubo que incorporar, aunque de manera subordinada, a los campesinos que hacían uso de la montaña. En este proceso, se fue creando una articulación de saberes territoriales de distinto cuño e intereses diversos: el de la conservación por parte de expertos e instituciones gubernamentales, por un lado, y el del aprovechamiento de un recurso natural - antes silvestre y ahora cultivadoque provee de ingresos necesarios para la manutención familiar. Si bien la creación y puesta en marcha de la RBLT adoleció de los mismos defectos identificados por Goldman (2003) y Bluwstein y Lund (2018) en Tanzania, con una planeación de arriba hacia abajo que excluyó totalmente a los habitantes del ANP en la definición misma del territorio de conservación, más adelante hubo una necesidad de articulación de saberes que posibilitó la consolidación y expansión de una actividad productiva que no se contraponía a la conservación, pero sobre todo que era conocida y apreciada por los usuarios de la montaña.
Por otra parte, hemos mostrado que en un espacio determinado pueden existir distintas territorializaciones creadas en diversos momentos históricos. Como señala Ther Ríos (2012): “El territorio es tiempo. Varios tiempos depositados. Entremezclados. Vividos" (p. 8). En ocasiones, una territorialización puede desplazar paulatina pero completamente a otra previamente desarrollada - el caso de la territorialización agraria derivada del reparto agrario, que después de varias décadas terminó finalmente con expresiones particulares del antiguo acceso comunal a la tierra-(Velázquez, 2019), en tanto que otras veces, distintas territorializaciones coexisten - la territorialización agraria y la territorialización para la conservación-. Cada una de estas territorializaciones está anclada en prácticas e intereses particulares, que pueden llegar o no a articularse. Además, a las diversas territorializaciones corresponden saberes territoriales distintos. Consideramos que es en este sentido que Ther Ríos (2012) afirma que "La Antropología del Territorio resemantiza el espacio, proyectándolo a dimensiones temporales entretejidas" (p. 8).

Un último aspecto que queremos subrayar es que los saberes locales no necesariamente están anclados a prácticas y cosmovisiones ancestrales, sino que muchas veces, como es el caso aquí presentado, pueden ser de creación relativamente reciente y estar asociados a actividades productivas inducidas por la demanda del mercado y la necesidad de 
proveerse de ingresos monetarios. ${ }^{17}$ Estos saberes locales no son estáticos, tienen una gran capacidad de adaptarse a nuevas realidades como ha quedado demostrado con el tránsito de la recolección al cultivo de la palma camedor. Un tránsito que ha necesitado un periodo de alrededor de quince años, al cabo del cual algunos de los primeros cultivadores actualmente se autonombran y se asumen públicamente como expertos en el cultivo de palma. ${ }^{18}$ En términos del modelo propuesto por Landini (2010), se trata de "saberes consolidados de incorporación reciente" ( $p$. $31)$, los cuales se suman a saberes territoriales de vieja data ligados a la agricultura (principalmente maíz y frijol, de la que formaba parte importante la labor de especialistas que hacían llover), la cacería, la pesca, la medicina tradicional que curaba enfermedades físico-emocionales y físicoespirituales, pero también la picadura de víboras de cascabel. Estos conocimientos, como todo saber, no han permanecido intactos, sino que en función de diferentes circunstancias se han modificado: en la década de 1930 se introdujo la caficultura en varias localidades de Soteapan, y en los años 1970 el Instituto Mexicano del Café introdujo nuevas prácticas de manejo de este cultivo que fueron adoptadas por los productores. También en esta década se empezaron a manejar semillas mejoradas de maíz y a usar agroquímicos; además, en algunas localidades se introdujo la ganadería bovina y sus propietarios debieron aprender a manejar el ganado. Al mismo tiempo, los especialistas que hacían llover prácticamente han dejado de actuar, principalmente porque han muerto y no ha habido quien tome sus lugares. Las prácticas de caza y pesca también han sufrido una merma, aunque se siguen realizando. No obstante, los curanderos, entre ellos algunos culebreros, continúan teniendo un número considerable de pacientes. Todos estos saberes, ligados siempre a conocimientos del territorio que se habita y ocupa, se articulan de diferentes maneras y se van adecuando a nuevas circunstancias.

\section{Referencias}

Bluwstein, J., \& Lund, J. F. (2018). Territoriality by conservation in the SelousNiassa Corridor in Tanzania. World Development, 101, 453-465. https://doi. org/10.1016/j.worlddev.2016.09.010 CONANP. (2006). Programa de conservación $y$ manejo. Reserva de la Biosfera Los Tuxtlas. México: CONANP. Recuperado de https://www.conanp.gob.mx/ que_hacemos/pdf/programas_manejo/tuxtla_final.pdf

Goldman, M. (2003). Partitioned nature, privileged knowledge: Communitybased conservation in Tanzania. Development and Change, 34(5), 833-862. https://doi.org/10.1111/j.14677660.2003.00331.x

González E., Dirzo, R., \& Vogt, R. (Eds.). (1997). Historia natural de Los Tuxtlas. México: UNAM.
${ }^{17}$ Una situación semejante es analizada por Landini (2010) en relación con aprendizajes campesinos en el municipio de Misión Tacaaglé, en la provincia de Formosa, Argentina.

${ }^{18}$ Taller de cultivo de palma impartido por palmeros popolucas del ejido San Fernando a campesinos nabuas de la comunidad agraria de Pajapan, realizado en la parcela del señor Silverio Cruz el 30 de abril de 2018.

\section{territarias 42-Especial}


Gutiérrez Campo, R. D. (2019). Entre el agua, la tierra y la gente: tensiones $y$ disputas por los usos de suelo de manglar en Alvarado, Veracruz, México. (Tesis de maestría, Centro de Investigaciones y Estudios Superiores en Antropología Social (CIESAS), Xalapa, Veracruz, México). Recuperado de https://ciesas.repositorioinstitucional. $\mathrm{mx} /$ jspui/bitstream/1015/921/1/ TE\%20G.C.\%202019\%20Ruben\%20 Dario\%20Gutierrez\%20Campo.pdf

INEGI. (2010). Censo de población y vivienda, 2010. México: INEGI.

Landini, F. (2010). La dinámica de los saberes locales y el proceso de localización del saber científico. Aportes desde un estudio de caso. Cuadernos de Desarrollo Rural, 7(65), 21-43.

Münch, G. (1983). Etnología del Istmo Veracruzano. México: UNAM.

Paré L., Velázquez, E., Ramírez, F., \& Graciano, O. (2017). Entre la investigación académica y la investigación acción: tres estudios de caso en Los Tuxtlas, Veracruz. En V. H. Reynoso, R. I. Coates \& M. de L. Vázquez (Eds.), Avances $y$ perspectivas en la investigación de los bosques tropicales y sus alrededores: la región de Los Tuxtlas (pp. 87-96). México: Instituto de Biología-UnAM.

Ramírez F. (2005). La palma mayán (Chamaedorea hooperiana Hodel): situación actual y evaluación de los efectos de la cosecha de hojas en la Reserva de la Biosfera Los Tuxtlas, Veracruz. (Tesis de maestría, México, UNAM).
Ramírez F. (1999). Flora y vegetación de la Sierra de Santa Marta, Veracruz. (Tesis de licenciatura, México, UNAM). de los Santos Espinoza, J., López Paniagua J., \& González, A. (2003). Informe de mercado de la palma camedor (Chamaedorea spp.). México: Grupo Mesófilo AC. Recuperado de http://www. grupomesofilo.org/pdf/proyectos / PFNM/palma_camedor.pdf

Ther Ríos, F. (2012). Antropología del territorio. Polis, Revista Latinoamericana, 11(32), 1-17. Recuperado de https:// journals.openedition.org/polis/6674

Varo Berra, R. (2002). La reforma agraria en México desde 1853. Sus tres ciclos legales. México: UdeG/UCLA.

Velázquez, E. (2006). Territorios fragmentados. Estado y comunidad indigena en el Istmo veracruzano. México: CIESAS-El Colegio de Michoacán.

Velázquez, E. (2019). Del acceso comunal a la tierra a la certificación parcelaria: cambios en la gobernanza agraria. $L i$ minaR. Estudios sociales y humanisticos, 17(2), 85-97. https://www.doi. org/10.29043/liminar.vl7i2.675

Velázquez, E., \& Ramírez F. (1995). Usos económicos de la selva de montaña en una reserva de la biósfera. En E. Boege, H. García \& P. Gerez (Coords.), Alternativas al manejo de laderas en Veracruz (pp. 203-222). México: SEMARNAP/Friedrich Ebert Stiftung. tersitarios 42-Especial 24 